\title{
Acute Psychosis After Bupropion Treatment in a Healthy 28-Year-Old Woman
}

\author{
Justin Bailey, MD, and Shannon Waters, MD
}

Family physicians commonly use bupropion for treatment of tobacco abuse. Here we present a case of acute psychosis after treatment with bupropion. It represents the first case of bupropion-induced psychosis at a low dose in an otherwise healthy patient.

\section{Case}

A 28-year-old woman presented with a chief complaint of tobacco abuse and a desire to quit. Her medical history was remarkable for one previous anxiety attack, which was self-limited and required no medical intervention, and occasional gastrointestinal spasms treated with hyoscyamine. The patient's surgical history was unremarkable; so was her family history, which was negative for psychiatric diagnoses. The patient's social histories revealed a 3 pack per year smoking history, minimal alcohol use, and no elicit drug use. Given her desire to quit smoking, the patient was started on bupropion (Wellbutrin SR, GlaxoSmithKline, Brentford, United Kingdom) $100 \mathrm{mg}$ daily for 1 week, with goal titration to $150 \mathrm{mg}$ twice daily by the end of week 2. Risk and benefits were discussed and the patient was told to call with any concerns.

Seven days into treatment the patient called stating she could not leave her home for fear that someone was going to hurt her and her children. In addition to the paranoia, the patient developed panic attacks, suicidal ideation, and auditory hallucinations suggesting she should hurt herself. Despite the abnormal psychiatric symptoms, orienta-

This article was externally peer reviewed.

Submitted 29 October 2007; revised 7 January 2008; accepted 11 January 2008.

From US Air Force Air Mobility Command, Travis Air Force Base, California.

Funding: none.

Conflict of interest: none declared.

Corresponding author: Justin Bailey, Family Practice, Travis Air Force Base Hospital, 101 Bodin Circle, Travis Air Force Base, CA 94535 (E-mail: justin.bailey-02@travis.af.mil). tion and memory were preserved. The patient refused to come to be evaluated and insisted that she would not hurt herself despite the new ideation, commenting that what she was experiencing was "silly" and "not real." When buproprion was discontinued, all symptoms resolved over the course of 1 week. At a 2-month follow-up she displayed no residual symptoms.

\section{Discussion}

The side effects from bupropion are many; however, cases of psychosis are rare. In 1985 Golden et $\mathrm{al}^{1}$ reported symptoms of psychosis in 4 patients institutionalized with psychiatric disorders. Each of these patients was started on high doses of immediate release buproprion, with psychosis occurring at various intervals (3 to 30 days) after the initiation of therapy. The psychosis experienced by these patients was characterized by hallucinations in the presence of intact orientation and memory and resolved with discontinuing or lowering the dose of the drug. In 1992, Ames et al ${ }^{2}$ described 3 similar cases in patients treated for bipolar disorder treated with lithium and buproprion. Each patient's symptom resolved with the withdrawal of the bupropion.

In 1999, Howard and Warnock ${ }^{3}$ wrote a Letter to the Editor espousing risk factors for bupropionassociated psychosis, specifically including a history of psychosis, concurrent use of a dopaminergic agent, and advanced age. In 2002 came the first reported case of psychosis in a young (29-year-old) man treated with bupropion for smoking cessation. This patient's history was significant for concomitant multi-substance abuse, including alcohol and marijuana. His symptoms appeared at a $300-\mathrm{mg} /$ day dose and resolved with discontinuation of bupropion. $^{4}$

There are 2 hypotheses regarding bupropionassociated psychosis. The first is related to bupropion's effect on dopamine inhibition. ${ }^{1,3}$ Specifically, it has been postulated that there is inhibition 
of dopamine uptake with buproprion. ${ }^{5}$ The defense of this theory is seen in the fact that dopaminergic side effects (insomnia, nausea, and vomiting) are more common with bupropion use versus amitriptyline use. ${ }^{6}$ Furthermore, patients on L-dopa plus bupropion were much more likely to develop symptoms of dopamine toxicity versus control groups of patients on L-dopa alone. ${ }^{7}$ Finally, increased levels of the dopamine metabolite homovanillic acid have been noted in patients who responded poorly to bupropion. This finding suggests that the dopamine has not been present in the circulation long enough to have it's proper effect. ${ }^{5}$

The second theory relates to bupropion's chemical structure, which is similar to amphetamine. Auditory hallucinations and paranoia associated with clear sensoria are shared symptoms with amphetamine toxic syndromes and bupropion psychosis. ${ }^{8}$ None of the patients had tactile hallucinations or skin pricking behavior which would complete the amphetamine syndrome.

This case is similar to the other cases mentioned because the patient's symptoms of psychosis developed 7 days after drug initiation and included paranoia and auditory hallucinations in the presence of intact orientation and memory. Given that the onset and complete resolution of her symptoms was associated with the start and stop of bupropion use suggest this medication as the cause of her psychosis. This case is unique because the symptoms developed at a low dose of bupropion in a young woman without any related psychiatric illness. Moreover, it is interesting to note that the patient was on hyoscyamine, which has anticholinergic properties. This case calls into question the interaction between bupropion and anticholinergic agents. It is well known that a delicate balance between acetylcholine and dopamine is required for brain homeostasis. This case suggests an additional theory for the development of psychosis with bupropion use, specifically, the concominant use of anticholinergic agents. Currently, there is no literature, including packet inserts, suggesting an interaction between anticholinergics and bupropion.

\section{Conclusion}

Many physicians are well versed in the use of bupropion for smoking cessation and depression. This represents the first case of bupropion-induced psychosis in a previously healthy patient with no comorbid substance abuse on low doses of the medication. In addition, this case brings to light the question, Is there a contraindication to prescribing bupropion with anticholinergic agents? Further studies will be necessary to elicit the answer to this question.

\section{References}

1. Golden RN, James SP, Sherer MA, et al. Psychosis associated with bupropion treatment. Am J Psychiatry $1985 ; 142: 1459-62$.

2. Ames D, Wirshing WC, Szuba MP. Organic mental disorders associated with bupropion in three patients. J Clin Psychiatry 1992;53:53-5.

3. William H, Warnock J. Bupropion-induced psycosis. Am J Psychiatry 1999;156:2017-8.

4. Neumann M, Livak V, Paul HW, Laux G. Acute psychosis after the administration of bupropion hydrochloride (Zyban). Pharmacopsychiatry 2002;35: 247-8.

5. Ferris RM, Cooper BR, Maxwell RA. Studies of bupropion's mechanism of antidepressant activity. J Clin Psychiatry 1983;44(5 Pt 2):74-8.

6. Chouinard G. Bupropion and amitriptyline in the treatment of depressed patients. J Clin Psychiatry 1983;44(5 Pt 2):121-9.

7. Golden RN, Rudorfer MV, Sherer MA, Linnoila M, Potter WZ. Bupropion in depression. I. Biochemical effects and clinical response. Am Gen Psychiatry Feb 1998;45:139-43.

8. Jaffe JH. Drug addiction and drug abuse. In: Gilman AG, Goodman LS, Gilman A (eds). Goodman and Gilman's the pharmacology basis of therapeutics, 6th ed. New York: Macmillan, 1980. 